\title{
AVALIAÇÃO DA ESTRUTURA NA ATENÇÃO PRIMÁRIA EM SAÚDE PARA O SUPORTE BÁSICO DE VIDA
}

\section{Fernanda Cassinelli}

Hospital das Clínicas da Faculdade de Medicina da USP, Brasil.

\section{Elizabete Santos Melo}

Escola de Enfermagem de Ribeirão Preto. Universidade de São Paulo, Brasil.

\section{Christefany Régia Braz Costa}

Escola de Enfermagem de Ribeirão Preto. Universidade de São Paulo, Brasil

\section{Renata Karina Reis}

Escola de Enfermagem de Ribeirão Preto. Universidade de São Paulo, Brasil
Autor correspondente:

Elizabete Santos Melo

elizabetemelo@usp.br
RESUMO: Descrever a estrutura das Unidades Básicas de Saúde (UBS) no atendimento para o Suporte Básico de Vida (SBV). Tratase de um estudo transversal, descritivo, com abordagem quantitativa, desenvolvido em 13 Unidades Básicas de Saúde de um município do interior paulista, no período de dezembro de 2013 a junho de 2014, por meio de entrevistas estruturadas com os responsáveis e observação da estrutura. Foi elaborado um roteiro específico para esse estudo. As unidades estudadas não dispunham de todos os materiais, equipamentos e espaço necessários para o atendimento de SBV. Apenas os itens bolsa-válvula-máscara adulto e luvas de procedimento foram encontrados em $100 \%$ das unidades. Constatou-se a não adequação de grande parte das UBS a requisitos estruturais mínimos para $\mathrm{o}$ atendimento de SBV, bem como lacunas frente à organização e disposição dos materiais.

PALAVRAS-CHAVE: Atenção Primária à Saúde; Reanimação cardiopulmonar; Emergências; Infraestrutura sanitária; Enfermagem.

\section{EVALUATION OF THE FIRST AID HEALTH STRUCTURE FOR BASIC LIFE SUPPORT}

ABSTRACT: To describe the structure of Basic Health Units (UBS) in attending the Basic Support of Life (SBV). A transversal, descriptive, quantitative study developed in 13 UBSs of a municipality in the interior of the state of São Paulo, Brazil, between December 2013 and June 2014, through structured interviews with people in charge and through the observation of the structure. A specific script was prepared for the study. Not all units had all the materials, equipments and space required for SBV care. Only items such as adult bag-valve-mask and gloves were extant in all the units. Results show that most UBSs were minimally prepared for SBV attendance, with serious gaps in the organization and disposition of materials.

KEY WORDS: First aid; Cardio-pulmonary reanimation; Emergencies; Sanitary infrastructure; Nursing.

\section{INTRODUÇ̃̃o}

No Brasil, a Política Nacional de Atenção às Urgências (PNAU) preconiza que a atenção para estes fins deve ocorrer em todos os níveis do Sistema Único de Saúde (SUS). Nesse contexto, a Atenção Básica (AB), como parte integrante da Rede de Atenção às Urgências (RAU), deve ser estruturada para prover atendimento resolutivo em casos de urgência considerados de baixa complexidade, e que não 
demandem de alta tecnologia, oferecendo o primeiro atendimento ao usuário, estabilizando quadros mais graves e encaminhando para outros níveis de atenção quando necessário ${ }^{1-2}$.

As Unidades de Saúde (UBS) representam parte da rede de atendimento pré-hospitalar fixo ${ }^{3}$. A qualidade do atendimento e o tempo entre o reconhecimento das urgências e a estabilização é essencial para evitar possíveis sequelas e até mesmo a morte. Para isso, este atendimento deverá ser realizado por profissionais qualificados e contar com recursos físicos e materiais adequados ${ }^{3}$.

Um estudo da Sociedade Brasileira de Cardiologia estimou que há aproximadamente 200.000 Paradas Cardiorrespiratórias (PCR) por ano no Brasil, sendo metade delas em ambiente hospitalar, e a outra metade extra-hospitalar ${ }^{4}$.

Denomina-se Suporte Básico de Vida (SBV) a abordagem inicial da vítima de PCR, a qual é composta por uma sequência primária de ações, e inclui rápida deteç̧ão da parada, compressões torácicas externas eficazes, desfibrilação precoce e atendimento avançado5.

Para que estas ações sejam realizadas com qualidade e eficiência, os profissionais de saúde devem ser capazes de reconhecer a ocorrência da PCR, iniciar rapidamente o SBV e, posteriormente, encaminhar o paciente para um serviço de maior complexidade onde serão realizadas todas as ações referentes ao Suporte Avançado de Vida (SAV) $)^{4,6-7}$.

Outra condição básica para organização da assistência em saúde é a avaliação dos serviços ${ }^{8}$. Neste sentido, um dos referenciais mais utilizados no Brasil foi proposto por Donabedian, que elaborou um quadro conceitual sobre avaliação da qualidade dos serviços?. Este modelo é descrito em três componentes: estrutura, processo e resultado.

A componente estrutura corresponde às características relativamente estáveis e necessárias ao processo assistencial, abrangendo a área física, recursos humanos (número, tipo, distribuição e qualificação), recursos materiais e financeiros, sistemas de informação e instrumentos normativos técnico-administrativos, apoio político e condições organizacionais ${ }^{10}$, e constitui como item essencial para o desenvolvimento das atividades de SBV.
Nesse sentido, faz-se necessário que as unidades possuam materiais básicos para o atendimento inicial de urgência, a fim de facilitar o acesso, garantindo assim a redução do tempo resposta e a maior eficácia do atendimento. No entanto, ainda são incipientes estudos que avaliem as UBS como forma de julgamento da implementação da PNAU.

Diante do exposto, o presente estudo tem por objetivo descrever a estrutura das UBS no atendimento aos usuários para o SBV.

\section{METODOLOGIA}

Trata-se de um estudo transversal, descritivo, com abordagem quantitativa, desenvolvido em 13 Unidades Básicas de Saúde (UBS) pertencentes ao distrito oeste de um município do interior paulista, no período de dezembro de 2013 a junho de 2014.

$\mathrm{O}$ distrito oeste apresenta o maior número de UBS, abrangendo a maior cobertura da atenção primária do munícipio estudado.

Foram realizadas visitas aos serviços e entrevista com os respectivos responsáveis, por agendamento prévio, via telefone. Os dados foram coletados por meio de entrevistas estruturadas com os enfermeiros das unidades, que aconteceram durante o horário de trabalho dos participantes, em sala privada.

As UBS funcionavam ao menos com a equipe mínima preconizada pela Política Nacional de Atenção Básica (PNAB), médico generalista ou especialista em saúde da família ou médico de família e comunidade, enfermeiro generalista ou especialista em saúde da família, auxiliar ou técnico de enfermagem e agentes comunitários de saúde ${ }^{11}$.

A pesquisa foi desenvolvida em dois momentos. No primeiro os enfermeiros responsáveis foram questionados sobre a organização dos materiais para o atendimento à PCR (organização dos materiais e conferência do carrinho de urgência).

Num segundo momento, foi executada a observação dos recursos físicos e materiais dos serviços, seguindo um roteiro pré-estabelecido, o qual foi elaborado apoiando-se no manual de "Acolhimento à Demanda 
Espontânea" como uma das diretrizes propostas para a reorganização da rede de atenção à saúde ${ }^{12}$.

A presença de materiais necessários para o atendimento do SBV foi organizada em: compressões torácicas representadas pela letra $\mathrm{C}$, ventilações $\mathrm{B}$ e a desfibrilação precoce D e foi considerado satisfatório; os matérias estavam presentes em todas as unidades.

Para análise, os dados foram armazenados e analisados por meio de recursos de estatística descritiva utilizando o software IBM ${ }^{\circledR}$ SPSS Statistics 20.0.

$\mathrm{O}$ estudo atendeu as normas nacionais de ética em pesquisa envolvendo seres humanos, tendo sido autorizada pela Secretaria Municipal de Saúde e aprovada pelo Comitê de Ética em Pesquisa sob protocolo de $n^{0} 1308 / 2011$, seguindo a resolução 466/2012. Os participantes assinaram o Termo de Consentimento Livre e Esclarecido (TCLE), sendo o anonimato garantido.

\section{RESULTADOS}

Foram avaliadas 13 Unidades Básicas de Saúde. Dentre as unidades 12 (92,3\%) adaptaram suas salas para atendimento de urgência, disponibilizando de espaço improvisado.

No que diz respeito à organização dos materiais para o atendimento às urgências, em cinco $(38,4 \%)$ serviços estes materiais encontram-se organizados em carrinhos de emergência. Quanto ao reconhecimento do carrinho, em seis (46,2\%) unidades eles estavam dispostos de maneira que facilitava a sua identificação e sem obstáculos em seu caminho.

Com relação à conferência do carro de emergência, constatou-se que em todas as unidades havia rotina de checagem destes materiais. Em nove (69,2\%) serviços os materiais são conferidos uma vez ao mês e em duas (15,2\%) não souberam especificar a periodicidade da conferência.

Importante ressaltar que nove $(69,2 \%)$ das unidades não atribuem profissional fixo para a execução desta tarefa, ou seja, vários profissionais em um mesmo serviço são incumbidos de realizar a conferência e checagem do carrinho de emergência.

Além disso, quando questionados sobre a utilização de protocolos para a checagem destes materiais, sete $(53,8 \%)$ unidades afirmaram não utilizar protocolos, conforme descrito na Tabela 1.

Tabela 1. Caracterização das Unidades Básicas de Saúde quanto à organização dos materiais de urgência, conferência e presença do DEA. Ribeirão Preto, SP, Brasil, 2014

\begin{tabular}{|c|c|c|}
\hline Variáveis & n & $\%$ \\
\hline \multicolumn{3}{|l|}{ Sala para atendimento de urgência } \\
\hline Específica & 01 & 7,7 \\
\hline Adaptada & 12 & 92,3 \\
\hline \multicolumn{3}{|l|}{ Organização dos materiais de urgência } \\
\hline Carrinho de emergência & 05 & 38,4 \\
\hline Caixa organizadora & 04 & 30,7 \\
\hline Carrinho de emergência + caixa & 02 & 15,3 \\
\hline Armário & 09 & 69,2 \\
\hline \multicolumn{3}{|l|}{ Localização dos materiais de urgência } \\
\hline Sem obstáculos & 06 & 46,2 \\
\hline Com obstáculos & 07 & 53,8 \\
\hline \multicolumn{3}{|l|}{ Conferência dos materiais } \\
\hline Sim & 13 & 100 \\
\hline \multicolumn{3}{|l|}{ Período de conferência } \\
\hline 1x ao mês & 09 & 69,2 \\
\hline $1 \mathrm{x}$ a cada 20 dias & 01 & 7,7 \\
\hline Semanalmente & 01 & 7,7 \\
\hline Não soube especificar & 02 & 15,4 \\
\hline \multicolumn{3}{|l|}{ Profissional que realiza } \\
\hline Auxiliar/Técnico em enfermagem & 10 & 76,0 \\
\hline Enfermeiro & 06 & 46,1 \\
\hline Farmacêutico & 03 & 23,0 \\
\hline Auxiliar de farmácia & 03 & 23,0 \\
\hline \multicolumn{3}{|c|}{ Utiliza protocolo de conferência dos materiais } \\
\hline Sim & 06 & 46,2 \\
\hline Não & 07 & 53,8 \\
\hline \multicolumn{3}{|l|}{ Qual protocolo utiliza } \\
\hline Elaborado pela unidade & 04 & 30,7 \\
\hline $\begin{array}{l}\text { Elaborado pela secretaria municipal } \\
\text { de saúde }\end{array}$ & 02 & 15,3 \\
\hline
\end{tabular}

$\mathrm{Na}$ Tabela 2, encontram-se os dados referentes à disposição dos materiais utilizados no SBV que foram analisados em todas as UBS, organizados de acordo com a sequência C-B-D de atendimento, preconizada pela American Heart Association 5 .

Considerando que a primeira sequência no atendimento é o $\mathrm{C}$, que diz respeito às compressões torácicas externas, foi observado que apenas uma unidade de saúde dispunha da prancha rígida.

$\mathrm{Na}$ avaliação dos materiais necessários para atendimento do $\mathrm{B}$, os quais correspondem à ventilação, todos os serviços contavam com sistema bolsa-válvulamáscara para adulto e 11 dispunham de torpedos de 
oxigênio. Na letra $\mathrm{D}$, que leva em consideração a presença do Desfibrilador Externo Automático (DEA), apenas uma unidade possuía o equipamento.

Com relação aos Equipamentos de Proteção Individual (EPI), indispensáveis em toda a sequência do atendimento, constatou-se que as luvas de procedimento foi o único material encontrado nas 13 unidades. Os itens máscaras simples, óculos de proteção e aventais foram classificados como insatisfatório, uma vez que não eram equipamentos presentes em todas as unidades.

Tabela 2. Caracterização da presença dos materiais utilizados para o atendimento de SBV em Unidades Básicas de Saúde. Ribeirão Preto, SP, Brasil, 2014

\begin{tabular}{|c|c|c|c|c|}
\hline Sequência & Itens & n & $\%$ & Classificação \\
\hline \multirow[t]{2}{*}{ C - Circulação } & Prancha rígida & 01 & 7,7 & Insatisfatório \\
\hline & $\begin{array}{l}\text { Saída de } \\
\text { oxigênio }\end{array}$ & 10 & 76,0 & Insatisfatório \\
\hline \multirow[t]{2}{*}{ B - Ventilação } & $\begin{array}{l}\text { Bolsa-válvula- } \\
\text { máscara } \\
\text { adulto }\end{array}$ & 13 & 100,0 & Satisfatório \\
\hline & $\begin{array}{l}\text { Torpedo de } \\
\text { oxigênio }\end{array}$ & 11 & 84,0 & Insatisfatório \\
\hline $\begin{array}{l}\text { D } \\
\text { Desfibrilador }\end{array}$ & $\begin{array}{l}\text { Desfibrilador } \\
\text { externo }\end{array}$ & 01 & 7,7 & Insatisfatório \\
\hline \multirow{4}{*}{ EPI* } & Luva & 13 & 100,0 & Satisfatório \\
\hline & $\begin{array}{l}\text { Máscara } \\
\text { simples }\end{array}$ & 12 & 92,3 & Insatisfatório \\
\hline & Avental & 10 & 76,0 & Insatisfatório \\
\hline & Óculos & 10 & 76,0 & Insatisfatório \\
\hline
\end{tabular}

*EPI: equipamento de proteção individual.

\section{DISCUSSÃO}

O sucesso no atendimento de uma PCR depende de alguns fatores relacionados ao paciente, à estrutura e aos profissionais envolvidos com o atendimento ${ }^{13}$. Portanto, destaca-se a importância de ter um local específico, de fácil acesso e sempre disponível para alocação de um desfibrilador e dos insumos necessários para o atendimento às urgências 2 . SSANDRONI $^{\text {. }}$

A política de acolhimento à demanda espontânea nas unidades básicas preconiza que o atendimento, em especial, às urgências e emergências envolva ações que devem ser realizadas em todos os pontos de atenção à saúde, entre eles, os serviços de $\mathrm{AB}^{3}$. No entanto, o processo de acolhimento ainda possui lacunas quanto a sua sistematização nos modelos de atenção à saúde, podendo refletir nas dificuldades organizacionais que interferem na resolutividade do processo de trabalho $0^{3,14}$.

Com relação às UBS estudadas, constatouse a ausência de diversos materiais e equipamentos necessários para o SBV. Os únicos materiais básicos considerados como satisfatórios foram à bolsa-válvulamáscara adulto e as luvas de procedimento.

Os resultados demonstram que realidade encontrada nos serviços não estão em consonância com PNAU, pois além dos materiais em déficit, há discordância relacionada à estrutura, ao dimensionamento e ao armazenamento dos mesmos nos serviços, bem como lacunas quanto à padronização e checagem.

De acordo com a portaria do Ministério da Saúde $\mathrm{n}^{\circ} 2048 / 2002$, todas as unidades devem ter um espaço devidamente abastecido com medicamentos e materiais essenciais ao primeiro atendimento/estabilização de urgências ${ }^{15}$.

A maioria dos materiais era armazenada no carrinho de emergência, caixas ou armários, e estavam dispostos em lugares que apresentavam algum obstáculo no acesso. Além disso, cada unidade possuía diferentes responsáveis pela checagem dos materiais, que poderia ser um auxiliar/técnico de enfermagem, enfermeiro, farmacêutico ou auxiliar de farmácia.

Segundo o parecer técnico do Conselho Regional de Enfermagem de São Paulo n ${ }^{0}$ 037/2013, o enfermeiro deve ser capacitado, e ter a responsabilidade técnica pela montagem, conferência e reposição de materiais do carro de emergência ${ }^{16}$. Porém, todos os membros da equipe de enfermagem podem realizá-la, desde que sob supervisão do enfermeiro.

Neste sentido, destaca-se a importância da elaboração de protocolos de materiais e equipamentos, bem como a manutenção da conferência e funcionamento dos mesmos para melhor padronização pela equipe de enfermagem. A organização dos recursos necessários ao atendimento de SBV possibilitará um atendimento 
eficaz, com segurança e qualidade, e consequentemente aumentarão as chances de sobrevida. Favorecendo a transformação efetiva da $\mathrm{AB}$ como porta de entrada principal do sistema de saúde ${ }^{17}$.

Ainda assim, para que as ações iniciais sejam efetivas, além dos materiais, os profissionais envolvidos no atendimento devem estar capacitados para atender a vítima de PCR, no primeiro atendimento, até que o Serviço de Atendimento Móvel de Urgência (SAMU) chegue ao local ${ }^{15}$.

Vale ressaltar que o déficit relacionado às condições de infraestrutura associado ao conhecimento teórico e prático insuficientes da equipe afetam o sucesso da reanimação ${ }^{18}$.

Apesar das políticas atuais apontarem a $\mathrm{AB}$ como elo na rede de atenção às urgências, a implantação destas ainda é um desafio a ser enfrentado, considerando que muitos profissionais não enxergam como sua responsabilidade este tipo de atendimento, o que fere o princípio da integralidade em saúde ${ }^{19}$. Além disso, há uma necessidade de transformação do modelo assistencial e investimento dos gestores para a adequação quanto aos recursos físicos, materiais e humanos.

\section{CONCLUSÃO}

O presente estudo constatou a não adequação de grande parte das UBS a requisitos estruturais mínimos para o atendimento de $\mathrm{SBV}$, bem como lacunas frente à organização e disposição dos materiais.

Os desafios encontrados para efetivação da PNAU na $\mathrm{AB}$ ainda são muitos. Portanto, espaços de discussão que contribuam para o fortalecimento da $\mathrm{AB}$ diante do seu protagonismo na rede de saúde, na produção e gestão do cuidado integral, são de grande valia.

Aponta-se como limitações deste estudo, a reduzida produção na literatura que contempla esta temática "Atendimento às Urgências na Atenção Básica", dificultando assim o processo de confrontamento dos dados encontrados com resultados de estudos prévios, e embasamento teórico para subsidiar a discussão.

Urgem desenvolver estudos com enfoque nesta temática, com o intuito de melhorar a qualidade do atendimento no nível primário de atenção, favorecendo assim a rede de atenção às urgências. Desta forma, os resultados sinalizam a necessidade de investimentos, preparo e adequação destes serviços, uma vez que são caracterizados como porta de entrada ao serviço de saúde e o primeiro contato do usuário com o sistema.

Por fim, espera-se que com esse pontapé inicial possa propagar essa discussão para outros municípios brasileiros, a fim de instigar a mobilização por parte de profissionais e gestores na realização das mudanças necessárias com enfoque nos atendimentos às urgências na $\mathrm{AB}$.

\section{REFERÊNCIAS}

1. Ministério da Saúde (BR). Secretaria de Atenção à Saúde. Departamento de Atenção Especializada. Manual Instrutivo da Rede de Atenção às Urgências e Emergências do Sistema Único de Saúde (SUS). Brasília: Ministério da Saúde; 2013.

2. Ministério da Saúde (BR). Portaria $n^{\circ} 1.600$, de 07 de julho de 2011. Reformula a Política Nacional de Atenção às Urgências e institui a Rede de Atenção às Urgências no Sistema Único de Saúde (SUS). Diário Oficial da União, 07 jul 2011 [acesso em 2018 out. 05]. Disponível em: http://bvsms.saude.gov.br/bvs/ saudelegis/gm/2011/prt1600_07_07_2011.html

3. Garcia AB, Papa MAF, Carvalho Júnior, PM. Estratégia da Saúde da Família: capacidade da equipe para 0 atendimento de urgência e emergência. Revista Nursing. 2012; 14(167):216-20.

4. Gonzalez MM, Timerman S, Oliveira RG, Polastri T, Dallan L AP, Araújo S, et al. I I Guideline for Cardiopulmonary Resuscitation and Emergency Cardiovascular Care - Brazilian Society of Cardiology: Executive Summary. Arq Bras Cardiol. 2013; 100(2):105-13.

5. Guimarães HP. Projeto de Destaques das Diretrizes da AHA. Destaques da American Heart Association 2015. Atualização das Direrizes de RCP e ACE. Dallas: American Heart Association; 2015 [acesso em 2018 out. 05]. Disponível em: https://eccguidelines. heart.org/wp-content/uploads/2015/10/2015-AHAGuidelines-Highlights-Portuguese.pdf 
6. Oliveira TA, Mesquita GV. Atendimento de urgência e emergência na Estratégia Saúde da Família. R Interd. 2013, 6(2):128-36.

7. Marcolino MS, Santos TMM, Stefanelli FC, Oliveira JAQ, E Silva MVRS, Andrade DF Júnior, et al. Cardiovascular emergencies in primary care: an observational retrospective study of a largescale telecardiology service.Sao Paulo Md J. 2017;135(5):481-7.

8. Furtado JP, Vieira-da-Silva LM. A avaliação de programas e serviços de saúde no Brasil enquanto espaço de saberes e práticas. Cad Saúde Pública . 2014; 30( 12): 2643-55.

9. Ayanian JZ, Markel H. Donabedian's Lasting Framework for Health Care Quality. N Engl J Med. 2016 Jul; 375(3):205-7.

10. Ministério da Saúde (BR). Secretaria de Atenção à Saúde. Departamento de Atenção Básica. Programa Nacional de Melhoria do Acesso e da Qualidade da Atenção Básica (PMAQ): Manual instrutivo para as equipes de atenção básica e NASF. Brasília: Ministério da saúde; 2017.

11. Ministério da Saúde (BR). Secretaria de Atenção à Saúde. Departamento de Atenção Básica. Política Nacional de Atenção Básica. Brasília: Ministério da Saúde; 2012.

12. Ministério da Saúde (BR). Secretaria de Atenção à Saúde. Departamento de Atenção Básica. Acolhimento à demanda espontânea / Ministério da Saúde. Secretaria de Atenção à Saúde. Departamento de Atenção Básica. 1. ed.; 1.reimpr. Brasília: Ministério da Saúde; 2013.

13. Citolino Filho CM, Santos ES, Silva RCG, Nogueira LS. Factors affecting the quality of cardiopulmonary resuscitation in inpatient units: perception of nurses. Rev esc enferm. USP. 2015; 49(6):907-13.

14. Coutinho LR P, Barbieri AR, Santos MLM. Acolhimento na Atenção Primária à Saúde: revisão integrativa. Saúde debate. 2015;39 (105): 514-24.

15. Ministério da Saúde (BR). Portaria n ${ }^{\circ} 2048$, de 20 de novembro 2002. Aprova o Regulamento Técnico dos Sistemas Estaduais de Urgência e Emergência. Diário
Oficial da União, 20 nov 2002 [acesso em 2018 out. 05]. Disponível em: http://bvsms.saude.gov.br/bvs/ saudelegis/gm/2002/prt2048_05_11_2002.html

16. Conselho Regional de Enfermagem de São Paulo. Parecer COREN-SP CT 037/2013, de 10 de julho de 2013. Dispõe sobre o Carro de emergência: composição, responsabilidade pela montagem, conferência e reposição. São Paulo: COREN; 2012 [acesso em 2018 out. 05]. Disponível em: http:// portal.coren-sp.gov.br/sites/default/files/parecer coren_sp_2013_37.pdf

17. Lemes RA, Silva MRS da, Silva BT, Gonzales RIC, Chagas MCS, Santos FDR. Sensitive assistance to basic care in a non-hospital emergency unit atendimient. Rev enferm UFPE on line. 2015; 9(11):9777-83.

18. Guilherme MIS, Oliveira CEFV, Silva ARM, Costa MFR, Vasconcelos RB. O atendimento de enfermagem em casos de parada cardiorrespiratória (PCR). In: $17^{\circ}$ CBCENF; 2014.P. 1-21; Belém, Brasil. Belém: COFEn; 2014 [acesso em 2018 out. 05]. Disponível em: http://apps.cofen.gov.br/cbcenf/sistemainscricoes/ anais.php?evt $=12 \& \sec =91 \&$ niv $=6.1 \& \operatorname{con}=10532$

19. Farias DC, Celino SDM, Peixoto JBS, Barbosa ML, Costa GM. Acolhimento e Resolubilidade das Urgências na Estratégia Saúde da Família. Rev bras educ med. 2015; 29(1):79-87.

Recebido em: 05/10/2018 Aceito em: 21/05/2019 